\title{
Identidad en el laberinto: La búsqueda del sentido étnico en San Pedro de Atacama
}

FRANCISCO RIVERA $^{1}$

\section{RESUMEN}

El presente artículo se refiere a la construcción contemporánea de la identidad atacameña, especialmente en San Pedro de Atacama, abordando a los agentes externos a la cultura atacameña, especialmente aquellos provenientes de la modernidad, a los cuales les ha cabido un rol protagónico en lo que actualmente conocemos como "cultura atacameña".

\section{ABSTRACT}

This paper refers to the contemporary of the atacameños identity, specially in San Pedro de Atacama, considering external agents, specifically those resulting from modernity, which have played a leading role in what is at present knows as "Atacama Culture".

Concuerdo con Polanyi (1992 [1957]) y Morandé (1984) cuando señalan que la modernidad se desarrolló como un proceso ideológico surgido naturalmente en Europa, producto de las transformaciones económicas y sociales del capitalismo emergente. Por su parte, América Latina presenta una situación diferente. Aquí el corpus ideológico de la modernidad fue importado y con él se inició recién el proceso de las transformaciones sociales y económicas, transformaciones que han marcado el devenir institucional de los estados, con la noción de desarrollo como norte, orientando las políticas gubernamentales en la gestión de educación, de producción industrial, de organización del aparato burocrático, entre otros.

Esta idea de desarrollo, por supuesto, fue el paradigma del debate intelectual en varias disciplinas, desde la sociología y la pedagogía hasta la economía. Como a su vez, también, continúa siendo bandera de lucha de los partidos políticos, postulando el desarrollo desde el liberalismo en la derecha, el

1 Instituto de Investigaciones Arqueológicas y Museo R. P. Gustavo Le Paige, s. j., Universidad Católica del Norte, San Pedro de Atacama, CHILE. estructuralismo en el centro, hasta el socialismo en la izquierda.

En todos los casos, un elemento común lo constituye la necesidad de cambiar la sociedad o hacerla más ligada al mercado o más ligada a los instrumentos políticos del Estado. El caso chileno se inserta, sin duda, dentro de esta tendencia, ya que el desarrollo como aplicación de la modernidad ha sido algo que ha distinguido el accionar de los gobiernos durante el siglo XX y buena parte del siglo XIX.

San Pedro de Atacama también ha sido parte de este movimiento modernizador. Lo fundamental es que si el modelo de modernidad ha sido ideológico para la América criolla, más aún lo ha sido para la América indígena, donde ha sido un modelo intrusivo y resemantizado con varias singularidades propias de sectores marginales, que reciben sólo una parte del ethos de la modernidad y el desarrollo, pero que no poseen el protagonismo político ni el sustento financiero con que concretar este desarrollo moderno.

Abordaremos ahora, someramente, la relación entre la modernidad y el desarrollo del pensamiento sociopolítico y económico.

Es algo bastante consensual que la inmensa mayoría de los pensadores de diversos ámbitos (religioso, político, militar, etc.) que reflexionaron en torno al poder hasta fines del siglo XVIII no concibieron una restricción tan profunda al poder institucionalizado como aquella que le entrega al mercado toda la capacidad de decidir, que el mercado en sí y por sí sea quien debe determinar la toma de decisiones económicas y más allá de lo propiamente económico, lo que Polanyi denominó el mercado autorregulador.

Sólo por nombrar a los connotados, mencionaremos a San Agustín, Calvino, Maquiavelo, Hobbes, Locke, Rousseau, Montesquieu, Kant y Clausewitz, entre otros, no abordaron este mercado autorregulador como una variable significativa dentro 
de las relaciones sociopolíticas en sus respectivas concepciones de sociedad. Este proceso se escapó, sin duda, de la tradición intelectual imperante hasta ese momento, la cual se centraba en la organización del Estado, el imperio del derecho natural y la secularización, entre otros.

Esta contradicción fue, sin embargo, absorbida por la sociedad occidental a costa de penurias, como la abismante desolación de los primeros cesantes masivos de la modernidad, despojados de sus trabajos por las máquinas de la incipiente revolución industrial. No existiendo en aquel entonces una estructura orgánica en la institucionalidad vigente que los protegiera, tanto en las organizaciones sociales como en las leyes, se podría afirmar que literalmente se morían de hambre.

Adam Smith y otros, por su parte, divergieron de la tradición intelectual, al no centrarse en las diversas variaciones del poder instituido, sino que plantearon la sociedad europea de la época en una situación límite, la del mercado autorregulador, donde el Estado (el poder instituido) no debía intervenir, para que las fuerzas productivas y distributivas dieran lo mejor de sí. Todo esto, al mismo tiempo que la Ilustración, con su imperio de la razón, evaluaba el modo como consciente y racionalmente se podían conducir los destinos de la humanidad, es decir, el punto más distante de la mano invisible de los agentes económicos, noción que propugnaban los pensadores de la economía clásica.

Análisis posteriores de intelectuales con posturas opuestas como Marx, Weber o Durkheim concuerdan en por lo menos un punto: que no se puede explicar la ascensión del capitalismo por y en sí mismo, sino que como una parte de un proceso sociohistórico y cultural mayor. Para Marx, por el desarrollo dialéctico de las fuerzas productivas, para Weber el cambio al individualismo en la vivencia religiosa en el norte de Europa y para Durkheim por la complexificación general de la sociedad debido entre otros a la división orgánica del trabajo. Todas ellas dinámicas internas macrohistóricas de la cultura occidental, con lo cual se explicaría que no sólo hayan resistido los embates sociales y políticos de 1830,1848 y 1871 , entre otros, sino que además se extendieran por todo el mundo con un sentido de expansionismo imperial.

En América Latina, este proceso macrohistórico no sucedió como en los países europeos, vanguardistas de la modernidad, por diversos motivos: por el sustrato poblacional indígena y negro, absolutamente ajeno a este desarrollo cultural, unidos a su vez al sustrato europeo español y portugués, marcados por la Contrarreforma (Morandé 1984) y por la descompensación inflacionaria en sus economías, caracterizadas por un exceso de metálico y un limitado desarrollo productivo.

En dichos términos, correspondió a las nacientes repúblicas latinoamericanas, influidas por las ideas de la Ilustración, dar cuerpo al proceso modernizador. Razón por la cual no partieron desde la raíz del proceso, sino que ya desde una etapa de consolidación, lo que hacía aún más exógena la importación de este modelo sociocultural. Se puede afirmar que para las nacientes repúblicas, Chile entre ellas, más que un proceso nacido en su devenir histórico fue más bien un modelo importado e implantado por su élite sociocultural poseedora del poder político y económico.

Se constituyó así en un modo de generar cultura, lo que podríamos denominar la cultura nacional hegemónica, creación que fue vital para el mantenimiento de las relaciones de poder, en un fenómeno que aún pervive con gran vigencia, y donde la historia de la etnia atacameña no es sino una de las tantas historias de pueblos y culturas, que desde una posición subalterna debieron interactuar con una posición de gran debilidad, ya que, además de no ser parte en lo absoluto del proceso, han tenido desde el contacto con Europa el pesado estigma de ser indígenas.

Otro proceso que es necesario mencionar en el análisis de la realidad sociohistórica del norte de Chile en general y de la región atacameña en particular, dice relación con el hecho de que en conjunto con la "construcción" de la identidad patria estuvo la consolidación jurídica del país como Estado, con el establecimiento de un marco de jurisprudencia adecuado para responder a las expectativas y las necesidades de los diversos sectores sociales de la población, en especial de los más hegemónicos en la naciente república. El gran ausente en estas bases fundacionales republicanas fue el territorio y los problemas étnico-demográficos, con la notable pero minimizada excepción de la etnia mapuche y su territorio de la "frontera", el territorio correspondía relativamente a las divisiones administrativas coloniales (Encina 1962) al igual que el tratamiento hacia las poblaciones indígenas asimiladas. 
En el extremo norte del país esta situación se mantuvo así hasta el fin de la Guerra del Pacífico (1884), en donde la consolidación del sentido patrio (en su amplia acepción) incluyó las prácticas de hostilización y expulsión de la población criolla peruano-boliviana del territorio recién conquistado a través de las Ligas Patrióticas u otros tipos de organizaciones con fines similares (González et al. 1993). Por el contrario, con la población indígena (aymara y atacameña), con la cual no se estaba inmediatamente en pugna, primó en principio la indiferenciación, para después irrumpir sistemáticas políticas de "asimilación” en los más variados ámbitos.

\section{San Pedro de Atacama y su laberinto cultural e histórico}

El devenir de San Pedro de Atacama muestra en extremo lo reseñado anteriormente, una fuerte imposición de un modelo cultural exógeno, con características particulares marcadas por las sucesivas reinterpretaciones culturales de la modernidad, desde el nivel continental latinoamericano y el nivel nacional, hasta el nivel regional (actual II Región de Chile). En términos burdos, los sampedrinos han recibido mayoritariamente una modernidad de "segunda o cuarta mano", la que ya contiene en sí una serie de entendibles incoherencias producto de la convergencia de diversos horizontes culturales. Atacama, en general, siempre ha permanecido ambivalentemente unida al escenario nacional, por una parte dependiente en lo administrativo y en lo territorial, y por otra, desplazada económica y culturalmente. En fin, ésta es la esencia de la marginalidad, es decir, la "integración producto de la postergación"; en dichos términos, la mantención de un modelo de centro-periferia como éste sólo es posible si se ha consolidado a través de un largo período, por lo cual es menester entregar una visión del desarrollo histórico de San Pedro de Atacama, desde su contacto con la modernidad.

Para la Corona española la importancia estratégica de Atacama La Grande (San Pedro de Atacama) fue en extremo significativa, por su condición de paso obligado en las rutas tanto norte-sur como las de este-oeste, lo que la convertía en un nudo de las transacciones comerciales de primera importancia de la administración hispana; Atacama se convirtió en la región de tránsito entre los grandes yacimientos mineros del altiplano, especialmente Potosí, y los puertos de embarque de la costa del Océano
Pacífico como Cobija (Núñez 1992). El que la región haya sido una zona de tránsito no era algo nuevo, pues era la continuación de la milenaria tradición de la movilidad giratoria de caravaneros (Núñez y Dillehay 1979) establecida como modo de integración armónica de diversos ecosistemas, más allá de las limitaciones del "archipiélago vertical” (Murra 1976).

Con todo, San Pedro en particular logró junto a Chiu Chiu una señera posición político-administrativa, estableciéndose como sede del Corregimiento durante el Período Colonial. Como hipótesis, planteamos que justamente esta importancia macroadministrativa limitó la expansión de un modo de vida más mercantilista por parte de la población local, y los fue inclinando más hacia la dependencia burocrática, bajo la égida de administraciones con mayor cobertura que el ámbito local, lo que en alguna medida, aún hoy tendría medida, aún hoy tendría importancia en la tradición de la conducta económica de los sanpedrinos, tan propensa a la dependencia subsidiaria y no a la acumulación de capital comercial, tanto de inversión como de consumo.

El corregimiento de Atacama tuvo su injerencia hasta lo que hoy es Susques en Argentina. La importancia de la presencia española colonial es algo aún no mensurado, no obstante esto, su presencia en las tradiciones orales, las expresiones folklóricas, el acervo religioso, etc., nos lleva a pensar que tuvo una trascendental importancia, ya no sólo en lo que hoy entendemos por tradicionalidad, sino también en la misma concepción de la modernidad, especialmente con la administración del corregidor Argumaniz (que se inicia en 1770), quien se inspiraba en las ideas del despotismo ilustrado (Hidalgo 1982). Aunque esta fuera una modernidad primitiva, ajena al modo de producción industrial y al surgimiento de los nacionalismos, dado que la Contrarreforma marcó el dominio español, lo que influyó en un fenómeno modernista a medias, sin el liberalismo económico ni la competición política de los nacionalismos.

Lamentablemente, el período de la administración de Bolivia comprendido entre 1825 y1879, es el menos conocido dada la carencia de una mayor cantidad de estudios documentales; a pesar de lo anterior, se puede señalar que se mantuvo el patrón colonial de tráfico entre los yacimientos minerales del altiplano y la costa pacífica (Cajías 1975), a través 
de la cuenca del río Loa hacia Lípez, y a través de San Pedro de Atacama, hacia la Puna de Atacama, en lo que hoy corresponde a Argentina.

Esta situación cambia profundamente con la administración por parte de Chile (1879 en adelante); en el quinquenio de 1885, una vez ganada la Guerra del Pacífico y consolidado el dominio geopolítico sobre la región por parte de Chile, se maximizó la explotación minera del desierto, así como también se dio inicio a las políticas de integración nacional en los planos de la jurisprudencia y la educación, entre otros. En un momento particular del país en que estuvo marcado por la "visión laica de progreso" (Paredes 1992), en donde el influjo de pensadores como Diego Barros Arana y Valentín Letelier, entre otros, fue decisivo en la construcción del sentido institucional con que el Estado chileno incorporó a esta región.

Es posible afirmar que el conjunto de la modernidad (tecnología y economía industrial, representatividad político-administrativa, masividad social, etc.) y el modernismo (creación científica y artística hiperespecializada) (Berman 1991) irrumpen con gran fuerza en San Pedro, pero sólo una parte del proceso. Su modelo ideológico, las relaciones de trabajo y la creación intelectual seguían estando marcadas por la tradición del período colonial; eso sin embargo no disminuyó la fuerza aculturadora de estos cambios, más aún, como hipótesis postulamos que esta modernidad "sesgada", a la larga ha tenido mayores consecuencias aculturadoras, que si hubiese sido una ruptura abrupta y evidente, en términos de la autopercepción del cambio. Al ser un largo e inalterado proceso de invisible aculturación, no se hace evidente la necesidad de rebelarse contra la violencia inmanente de la misma, sino simplemente se exacerba la pasividad. En resumen, el carácter atenuado de la dominación de los bienes simbólicos impide una toma de conciencia contestataria frente al proceso.

Hoy, en estudios cualitativos (Rivera 1993Ms), aparece una fortísima división interna de la sociedad sanpedrina, en donde se hace distinción entre los más indios, los llamados despectivamente coyas, y los atacameños (sanpedrinos), que se autoperciben como más blancos. Ahora, determinar con exactitud quiénes son los coyas, es algo difícil dado lo difuso de la denominación; pueden ser todos los que viven en el altiplano, los transcordilleranos, o sólo los bolivianos. Considero que ésta es una de las consecuencias más ingratas del proceso de transferencia del modelo de la modernidad en Atacama. Sin duda, ésta no es la única muestra de las graves incoherencias de lo que hemos denominado "el modelo cultural impuesto", dado que si se eliminan verticalmente estas subdivisiones se atacan los ejes de las relaciones de poder en el interior de la comunidad, con lo cual se desperfila la misma, provocando así un severo deterioro organizacional y de autogestión de la comunidad, que dicho sea de paso es algo que está ocurriendo ahora con la presencia del Estado en la región; y por otra parte, si se exacerban estas divisiones internas resultan relaciones sociales tan anacrónicas que poco o nada se puede insertar en la ahora aún más cambiante modernidad.

Dada la carencia de estudios sobre documentos de Atacama en este siglo, no es posible avalar cabalmente toda la información resultante del análisis de la historia oral, obtenida en entrevistas en profundidad, lo que se hace particularmente necesario para dilucidar el rol que le ha cabido al Estado en la construcción de la identidad cultural de los atacameños contemporáneos. De lo que no cabe duda es que las políticas gubernamentales han sido protagonistas de la mayoría de los cambios socioculturales que han marcado a los atacameños. Preliminarmente, es posible postular la existencia de dos períodos en este siglo bien diferenciados en lo que se refiere a la orientación de la presencia del Estado y sus consecuencias societales en Atacama en general y en San Pedro en particular, frente a lo cual hemos fijado arbitrariamente el año 1957 como el hito que separa ambos períodos.

El primer período, según lo recuerdan los atacameños, se caracterizaba por la existencia de una sociedad altamente jerarquizada, donde su clase dominante explotaba al máximo su condición de intermediario entre la sociedad nacional y la sociedad local; en especial, en aquello que se refiere al tráfico de ganado trasandino con el cual se alimentaba a la creciente población minera y urbana. Conjugando hábilmente los estándares tradicionales de trabajo, en especial la arriería, con la mercantilización moderna, fue transformándose esta clase acomodada en un híbrido que tenía la raigambre aristócrata colonial y además se manejaba con prácticas de acumulación de capital extracomunidad.

En una doble estrategia, por una parte la mantención de relaciones simbólico-laborales tradicionales, marcadas por el trueque y la reciprocidad, y por otra, una conexión monetarizada con los mercados 
alimentarios que se manejaban en metálico; con lo cual podían traer ganado de Argentina, 30000 cabezas al año en su momento de auge según Aranda (1964: 58), y a su vez enviar productos manufacturados de alta calidad (generalmente europeos) a esa región de Argentina, muy distante de su capital federal. Estos productos eran relativamente comunes en Chile dada la capacidad adquisitiva, producto del auge minero; además, es necesario recordar que los inversionistas técnicos de alta calificación eran normalmente europeos o norteamericanos (lo que aseguraba el mercado de consumo).

Esto no hubiese sido posible sin la orientación de Estado rentista como era el chileno en aquella época, preocupado más, como dijimos, por la consolidación geopolítica que por una real expansión de su aparato burocrático, situación que era común en todo el país y no sólo en esta región. Este enfoque sufre un vuelco por la propia dinámica institucional del Estado, dado el agotamiento del sustento social del modelo de Estado del llamado "parlamentarismo" (aunque realmente fue un presidencialismo más tenue) (Encina 1962; Heise 1979). Lo que culmina con la promulgación de la Constitución de 1925 y la aparición de las leyes sociales, entre otras, lo que llevó a una intervención más directa del aparato estatal en la vida nacional, para lo cual tuvo que desarrollarse, especialmente en el plano económico.

Lo anterior se hizo notar en forma más indirecta. Lo que por el contrario marcó directa y decididamente fue la crisis de la industria del salitre, la que tuvo su tiro de gracia con la crisis mundial de la economía en 1929. Los despidos fueron masivos, producto de la serie de cierres de oficinas salitreras, con lo que disminuyó notablemente la demanda de carne, así como también la oferta de los bienes manufacturados como consecuencia de la caída del poder adquisitivo en general. Con lo que el rol de intermediarios de los sectores acomodados de San Pedro cayó en la obsolescencia, quebrando el sistema de tráfico de ganado. Este sistema terminó por desaparecer en 1948, con la construcción del ferrocarril Socompa-Antofagasta, que continuaba el tramo Salta-Socompa; ya no sólo había menos demanda de ganado, sino que era mucho más rentable subir el ganado al ferrocarril en Salta y bajarlo en Antofagasta, con lo que San Pedro quedó fuera de dicho circuito económico. ${ }^{2}$

2 Viviana Conti de la Universidad Nacional de Jujuy (Argentina) plantea que el interés mayor por la construcción del Ferrocarril Salta-Antofagasta respondió a las antiguas aspiraciones de
Tanto la crisis económica generalizada como la dinámica institucional del país (especialmente en lo que se refiere a modelos de gobernabilidad) obligaron a garantizar la presencia gubernamental con personeros del Estado jugando papeles protagónicos, incluso en rincones tan apartados como San Pedro de Atacama, en donde esto se manifestó ya no sólo en un control de la territorialidad (salvaguarda de fronteras especialmente), sino que ahora se intervenía en la productividad y en las alternativas económicas de la región, a través del organismo creado con ese fin: la Corporación de Fomento de la Producción (CORFO); esta nueva orientación gubernamental involucró a todas las reparticiones estatales.

Como era de esperarse, una sociedad tan dependiente como la sampedrina fue marcada profundamente por estos cambios; además, es necesario considerar el alzamiento de la gran minería del cobre con una nueva realidad laboral lo que será tratado más adelante. No se puede explicar el actual estado de las relaciones sociales en San Pedro de Atacama sin referirse a este vuelco en la institucionalidad interna de la comunidad, la nueva red de canales de regadío construida entre 1960 a 1964, la Cooperativa Agrícola, la Junta de Adelanto, y el Club de los Cholulos, todos ellos de 1957 (de allí que fuera seleccionado como hito temporal), además la absorción de mano de obra por el mineral de Chuquicamata, han marcado los nuevos tiempos en San Pedro. Tiempos que como primera consecuencia, al cambiar la realidad socioeconómica, desarticularon los basamentos del poder local tradicional, lo que ha culminado con la fundación de la Municipalidad de San Pedro de Atacama en 1980. Es difícil concebir una mayor presencia del Estado que ésta, por lo que ha existido un verdadero éxodo de las tradicionales familias dirigentes, que ya no se sienten sustentadas en la legitimidad de su prestigio. Esta realidad ha sido acompañada de una creciente invasión de afuerinos en el pueblo, acrecentada en los últimos tiempos por el auge del turismo.

los inversionistas locales del noroeste argentino de contar con una vía de comunicación expedita con la cual poder trasladar las riquezas mineras desde el interior hasta los puertos de embarque tanto Atlántico como del Pacífico. Siendo el transporte de ganado una actividad secundaria del ferrocarril en cuestión (V. Conti com. pers. 1993). 
No poseemos, por el momento, antecedentes sobre el monto y el origen de los ingresos en el inicio de este siglo, pero ya en la segunda mitad del mismo es evidente que las actividades agropecuarias son insuficientes como para cubrir el sustento de una familia promedio en San Pedro; esto ha sido reseñado por Lobos (1953), Aranda (1964), el Taller de Estudios Andinos (1993Ms), por lo que la búsqueda de fuentes alternativas de ingreso familiar es imprescindible para su sobrevivencia, todo lo cual conlleva el disgregar la fuerza laboral en trabajo asalariado (p.e., en la minería), restringir el consumo, y ampliar la búsqueda de beneficios de las rentas del Estado: jubilaciones, pensiones contra la pobreza, subsidios múltiples, etc. Esta situación aumenta el grado de dependencia de la comunidad frente a la sociedad mayor, y trae la pérdida consiguiente de la capacidad de autogestión; aunque ahora se percibe a partir de la misma sociedad mayor, utilizando la recientemente promulgada "ley indígena", se pide justamente lo contrario, vale decir, una operativa autogestión. No cabe duda de que la reetnificación a partir del Estado, así como también el desenvolvimiento del poder local en el contexto de la "democracia representativa", a partir del retorno de la democracia en 1990 (con el gobierno de Aylwin), es el comienzo de una nueva etapa en el devenir histórico de la etnia atacameña; por el momento sólo podemos avizorarla ya que aún no se perfilan con nitidez sus consecuencias.

\section{La marginalidad como estrategia contra la postergación}

Este punto podría haber sido denominado "la marginalidad como consecuencia de la postergación", pero nos decidimos por la primera opción, ya que no pretendemos desconocer la avasalladora hegemonía que la sociedad mayor ha ejercido sobre la etnia atacameña, por un lado asimilándola, y por otro, postergándola a sectores subalternos de la sociedad. No obstante esto, creemos que existe un punto donde no se ha puesto toda la atención que éste amerita en los distintos trabajos que abordan la problemática atacameña actual y es el modo en que los atacameños han buscado integrarse a la sociedad chilena.

La base de este argumento es la hipótesis de que el corpus de la cultura atacameña se desarticuló progresivamente durante el Período Colonial y el siglo XIX, perdiendo su coherencia sistemática y la capacidad de dar respuestas solventes a las diversas inquietudes y necesidades de sus partícipes. Frente a lo cual no es de extrañar que en este siglo, en los relatos etnográficos sobre historia oral, existan varios ejemplos de una búsqueda de vinculaciones externas a la comunidad, con elementos tanto del poder político como del poder económico, ambos pertenecientes a la sociedad nacional. ${ }^{3}$ Observada con parámetros urbanos o de centros proletarios la magnitud de este fenómeno parecería mínima, pero lo importante es señalar que por lo menos un sector de sanpedrinos ya en la primera mitad de este siglo puso su voluntad en la búsqueda de relaciones con la sociedad mayor y apostó por el desarrollo en la modernidad.

Como es esperable, el acceso a una solvencia económica, al prestigio social y al logro de una capacidad de negociación política fue algo difícil de alcanzar para la mayoría y habitualmente este ascenso estuvo asociado a prácticas de apropiación de bienes y del trabajo en el interior de la comunidad, que nada tienen que envidiar al surgimiento de la protoburguesía en otros lugares del orbe. En conjunto con esto y en número significativo para una comunidad de este tamaño demográfico, llegaron a San Pedro una serie de chilenos, argentinos y croatas, entre otros. Ellos se unieron a la actividad económica más poderosa de la época: la minería; unos directamente ligados a pequeños y medianos yacimientos de azufre y de cobre fundamentalmente y, los más, vinculados a los centros de la gran minería a través de la actividad comercial, especialmente con las oficinas salitreras y el mineral de plata de Caracoles. Aquí la principal actividad comercial era el tráfico de ganado argentino, que aumentaba a los mencionados centros mineros y a las ascendentes ciudades de la zona norte del país.

Otra importante forma de relacionarse fue integrándose como masa laboral en el enorme centro cuprífero de Chuquicamata. Si bien no es éste el único trabajo donde se menciona este proceso, las interrogantes que surgen ahora están relacionadas con:

3 Una muestra de esto es la temprana militancia política en algunos sectores de la comunidad, tanto en los inicios de este siglo como pudo apreciarse en la crisis de 1924, o en la Ley de Defensa de la Democracia del gobierno de González Videla (1946-1952), donde hubo sanpedrinos relegados en Pisagua. 
a) ¿Cuántos fueron los atacameños de San Pedro que se acercaron a estas actividades, teniendo y no teniendo éxito? Lo más difícil es evaluar cuántos fueron los que no tuvieron éxito; pienso que fueron bastantes, sólo baste mencionar la gran e importante población de atacameños que viven en la pobreza en las poblaciones de Calama, tales como la "23 de Marzo" o la "Gustavo Le Paige". Sus habitantes son en su mayoría atacameños que reemplazaron su modo de vivir rural tradicional por el medio urbano.

b) Otra interrogante que surge es: ¿cuál ha sido la influencia que estos sectores han ejercido sobre sus poblaciones de origen? Dado que no existen datos fidedignos, tampoco es posible referirse a ello más allá de hipótesis preliminares. Lo que aparece como indiscutible es que los atacameños que viven en Calama ejercen una influencia decisiva en lo que se refiere a la cultura organizacional en las comunidades atacameñas.

Este es el meollo del punto en cuestión. La marginalidad (pobreza), siguiendo a Lewis (cit. en Anta 1992), es entendida como un corpus cultural definido autorreferente, surgido de patrones culturales divergentes de la sociedad mayor, y más aún, de acuerdo con Valentine (1970), quien la trató (a la pobreza y/o marginalidad) como una subcultura subalterna dentro de la sociedad mayor, producto de relaciones no-igualitarias de hegemonía en el interior de la propia sociedad. La hipótesis que sustento es que en este siglo por lo menos los habitantes de San Pedro, en conjunto con la segregación que como indígenas les ha sido impuesta desde la sociedad nacional, han procurado como estrategia de inserción (y/o integración) en la sociedad acercarse al sector de la sociedad mayor más permeable, no necesariamente el menos segregacionista, pero sí el que pareciera ofrecerles menos trabas de ingreso: el mundo de la marginalidad urbana y la llamada cultura popular. Sin duda el estudio de esta interacción semántica es una de las necesidades más apremiantes para entender el actual proceso de transformaciones de la sociedad sampedrina en particular y atacameña en general, ya que por el momento sólo se disponen de estudios preliminares (Rivera 1993Ms).

\section{Las divisiones internas en la comunidad de San Pedro de Atacama}

Con gran seguridad es posible afirmar que uno de los puntos menos tratados en la literatura actual es la existencia de profundos divisionismos internos en las comunidades andinas en general y en las atacameñas en particular. Desde este ángulo, San Pedro de Atacama es tal vez uno de los lugares donde más profundamente se ha vivido esta realidad, tanto en los aspectos económicos y políticos, a partir de una serie de procesos descritos anteriormente, como también en el plano social y cultural, y últimamente con el ingreso de las agrupaciones protestantes de diversa índole, estas divisiones intracomunidad se han profundizado hasta alcanzar el plano religioso.

Consideramos poco sustentable la visión de las comunidades indígenas como exentas de rencillas y problemas de convivencia cotidiana; no está de más señalar que al ser San Pedro una comunidad relativamente pequeña, que desde hace ya largo tiempo es sometida a un creciente bombardeo de agentes exógenos, que en este último período tienen su más clara representación en la máxima presencia del Estado: la Municipalidad de San Pedro de Atacama, por una parte, y por otra la masiva afluencia de turistas nacionales e internacionales, y los inversionistas de todo tipo que explotan dicha industria.

En estas condiciones visualizamos las diferenciaciones internas como una consecuencia no esperada del proceso de resemantización que los atacameños han hecho de las mencionadas influencias extemas, en donde lo que más impacta es la división en torno a quién es más y quién es menos indio; en este caso quienes se consideran realmente atacameños y quienes son considerados despectivamente más indios, a quienes denominan coyas, sin que exista al parecer un consenso absoluto sobre quiénes son efectivamente los coyas. En términos generales, se les denomina coyas a las personas que provienen del altiplano, de las pequeñas localidades aledañas sobre los 3000 m.snm:

“...Y ahora llenaron San Pedro de coyas, antes se traían algunos para trabajar con los animales, ellos tenían que vivir ahí mismo, con las ovejas, durmiendo cerca de los corrales o en las pircas, pero no se los dejaba vivir en el pueblo, en cambio ahora hay más coyas que sampedrinos en el pueblo..." (O.C.T. 42 años, varón)

Para abordar este tema, postulamos por lo menos dos ámbitos convergentes, en lo referente a la estructuración actual de la sociedad atacameña: 
a) La sociedad indígena prehispana en los oasis del Desierto de Atacama era altamente desarrollada, poseyendo en sí notables diferenciaciones sociales, propias de una sociedad jerarquizada, lo que tenía su contrapunto en los múltiples sistemas comunitarios en la tenencia de la tierra y la organización de trabajo, entre otros. Todo lo cual conformaba un sutil y bien logrado equilibrio, el cual fue roto con la conquista española, con lo que se desarticuló este sistema de equilibrios y se desperfiló el trasfondo ideológico que lo sustentaba, con lo cual, así como mantiene parcialmente el sistema comunitario, también se manifiesta fragmentariamente este tipo de diferenciación social tradicional. Sin duda, la mayor consecuencia de esta desarticulación es la crisis del liderazgo tradicional, lo cual se ha visto acrecentado especialmente en los últimos años, al tenor de la verdadera invasión que la sociedad mayor ha hecho en San Pedro de Atacama.

b) El otro punto que es absolutamente complementario con lo anterior es cómo la comunidad atacameña ha recepcionado y resemantizado las categorías ideológicas que le dan fundamento a las profundas diferenciaciones internas que sustentan nuestra cultura occidental, desde el racismo a las diferencias de clase. En una visión somera, se podría pensar que sólo se encuentra presente este segundo ámbito en San Pedro, pero creemos que no es así, pues no es posible pensar en una aculturación total, dado que nadie puede vivir sin cultura. Consideramos que las diferenciaciones son más visibles dada la crisis de legitimidad de la cultura indígena en esta comunidad, que lo que sería propiamente atacameño. Estos prejuicios, como el mencionado, son relegados para los ambientes más íntimos y reservados; ésta es una muestra más de cómo la esfera pública de la cultura ha sido mayoritariamente dominada por la cultura de la sociedad mayor.

La conjunción de estos dos ámbitos y de otros eventualmente influyen decididamente en las relaciones sociales y en la capacidad de gestión de las organizaciones de diversa índole que se conforman en el seno de la comunidad de San Pedro; esto se puede verificar tanto en el pasado como en el presente, por lo que es menester tener en cuenta estas diferenciaciones, ahora en esta época de cambios, producto de la "ley indígena". Como ejemplo de esto transcribo literalmente las siguientes opiniones de informantes sanpedrinos entrevistados:
“... Antes había más respeto, nos respetábamos más los unos a los otros, ahora ya no es lo mismo... San Pedro se llenó de mucho Machuqueño, Talabreño, Cameño..., en esa gente no se puede confiar..." (A.L. 70 años, varón)

“... Ve la Punta de Diamante (la población con ese nombre), está llena de Coyas de Talabre, de Río Grande; ellos se vienen pa'San Pedro, los de San Pedro se van pa'Calama..." (G.A. 46 años, mujer)

Desentrañar quiénes son los coyas dentro del universo simbólico de los sampedrinos es, sin duda, algo complejo. Se produce la mencionada convergencia entre las diferenciaciones sociales de origen interno y las de origen externo. A los coyas, como se dijo, se les asocia en general con aquellos poblados del altiplano, pero no solamente ahí. Aunque no existe consenso al parecer, los coyas serían aquellos habitantes más ligados a lo quechua-aymara, situados especialmente en la cuenca superior del río Loa, como la localidad de Qosqa, y por continuidad en las localidades de la cuenca del Salar y que están culturalmente ligadas al complejo Loa-Salado, como Machuca y Río Grande. Otro acápite es considerar que dicha denominación es otorgada por los tradicionales habitantes de los oasis piemontanos como San Pedro y Toconao, quienes comparten una historia hispana común durante el Período Colonial, y ahora compiten quién es más blanco o quién es menos indio.

En una suerte de geografía del prejuicio, podemos señalar que los habitantes de poblados más ligados con la conexión argentina de personas y bienes como Socaire y Peine tanto por su contacto reproductivo con los arrieros argentinos, como con los cazadores de chinchillas (provenientes del sur de Chile) de fines del siglo XIX y principios del $\mathrm{XX}$, son bastante mejor considerados que los coyas puros, y desde luego, que los braceros inmigrantes bolivianos. Cabe señalar que las localidades intermedias en entre estos polos, como Talabre, Soncor, Camar, Tilomonte, etc., tampoco cuentan con un gran prestigio sociorracial, siendo normalmente agrupados bajo el mismo denominativo.

Hay que ser enfáticos, cualquier intento de coadyuvar a los atacameños en su etnodesarrollo debe tomar en cuenta estas profundas divisiones internas. Pensamos que mucho del inmovilismo de la comunidad, detectado en múltiples ocasiones por 
demasiados proyectos de relativo éxito, y en las variables de conducta económica, y socioorganizacional, se han visto marcadas, sin duda, por la falta de impetuosidad económico-administrativa que los occidentales en su mayoría exigen como requisito básico para el bien logrado desarrollo.

\section{La gran minería como agente de cambio sociocultural}

Como se reseñó anteriormente, existe una gran importancia para la economía doméstica en San Pedro de Atacama, en lo que se refiere a los ingresos extraprediales tanto del sector de los servicios como en el trabajo asalariado de índole minero, proveniente de la pequeña minería local.

Pero existen fuentes de ingreso más allá del ámbito local, especialmente provenientes del Estado, como ya se mencionó, por lo que ahora nos dedicaremos al que consideramos el segundo gran agente externo de transformación económica y sociocultural: la gran minería, y aquí sobresale con preeminencia el enorme yacimiento de cobre de Chuquicamata, cuyo gravitante rol en la zona se prolonga desde 1912, fecha en que comenzó a operar industrialmente la compañía Chilean Exploration.

Es menester señalar que la importancia minera ha estado desde tiempos coloniales produciendo el último gran auge mercantil en la zona gracias al tráfico del ganado argentino, en un proceso ya explicitado antes. Con el colapso de la minería de nitratos a gran escala, se debilitaron también las redes del poder local y este debilitamiento tuvo su debacle final con la llegada de los funcionarios del Estado preocupados de la producción y la distribución. También esto ya fue descrito, pero lo que aparece como más significativo para los informantes es el rol de Chuquicamata.

A diferencia de lo que ocurrió en el pasado mercantil, en la lógica transnacional de la compañía tenía poca o ninguna importancia el poder local; lo fundamental no era relacionarse con las élites para acceder a insumos locales o transandinos, eso ya estaba solucionado con una solvente red caminera, más ferrocarriles, las que suplían con mucho, cualquier competencia local. Pero lo que sí se hacía imprescindible era una mano de obra barata y eficiente, por lo que el objetivo prioritario se centró en los lugareños de la más baja condición, fundamentalmente coyas en terminología local, los cuales al provenir de una economía de trueque resultaban muy baratos en su convertibilidad monetaria. Por otra parte su eficiencia radicaba en su milenaria adaptación fisiológica a las rigurosas condiciones medioambientales y, desde luego, por la rudeza de sus vidas podían adaptarse a las severas condiciones laborales comunes en la región.

Como era de esperarse, esta nueva situación trajo consigo un verdadero cataclismo en las relaciones sociales existentes, ya que los sectores tradicionalmente más postergados tuvieron un acceso más directo que cualquier otro a la modernidad. Al convertirse en asalariados de este gran mineral, tuvieron acceso ellos y sus familias a la educación, la salud y el dinero metálico, entre otros, en una mayor proporción que si se hubiesen quedado en San Pedro. Pero lo más importante para nuestro estudio es su apertura a nuevas culturas organizacionales, propias de la modernidad, tales como la cultura sindical como obreros de Chuquicamata, y a la cultura poblacional en las barriadas de Calama y del propio Chuquicamata, con lo cual la interrelación entre la tradicionalidad y la modernidad se amplió a niveles no esperados, lo que ha traído insospechadas consecuencias. En este contexto se fue volviendo obsoleto el sistema de relaciones sociales que se sustentaban en la red de poder tradicional, y en un creciente proceso de dependencia de bienes materiales y simbólicos de la población atacameña residente en San Pedro con aquella que emigró a Chuquicamata. Una muestra de esta dependencia la constituyen las ayudas familiares que provienen de esta fuente y, que incrementan el ingreso extrapredial de los que permanecen en San Pedro de Atacama. Además, pasó a convertirse en un modelo de éxito personal y familiar indiscutible el trabajar en la gran minería y este tipo de ingreso extrapredial muestra a nuestro juicio como las viejas estructuras de reciprocidad se reformulan, adaptándose a la nueva y cambiante realidad, siendo una pequeña muestra de la constante resemantización cultural que los atacameños hacen de su entorno.

Consideramos que esto llegó a tal nivel, que hoy no es posible entender el corpus cultural de los atacameños sin tomar en cuenta por lo menos lo que dijimos, la cultura sindical y la cultura poblacional, ya que a través de ella se han masificado nociones nacionales sobre la política contingente, la economía, y por supuesto, cánones éticos y estéticos propios de la nacionalidad moderna, los que si antes (hace 
unos 50 años) ya se consideraban importantes, ahora lo son más aún, lo que relativiza aquellas nociones intelectuales que buscan una suerte de pureza cultural entre los atacameños.

\section{Conclusiones}

En lo que se refiere al impacto de la intervención del Estado en la región atacameña, además de los procesos mencionados en el pasado, hoy están ocurriendo cambios trascendentales ya no sólo en lo que respecta a la "ley indígena" y a la "democratización del gobierno local", ya mencionadas antes, sino además la constitución orgánica del poder local está cambiando su orientación, de ser una mera cuña del poder central en las comunidades, ahora con el gobierno democrático, ha dotado a las municipalidades de una capacidad de gestión como nunca la tuvo antes, como la "Ley de gobierno y administración regional", "La nueva ley de patentes mineras", "La nueva ley tributaria" (llamada la reforma tributaria), además del concurso de organismos especialmente creados para el desarrollo autogestionado de las comunidades pobres, como el Fondo de Solidaridad e Inversión Social (FOSIS), la presencia de Organizaciones No Gubernamentales, así como la revitalización de la presencia de organismos como el Instituto de Desarrollo Agropecuario (INDAP) y la Dirección de Riego, entre otras. Todo esto es apoyado por el Fondo Nacional de Desarrollo Regional, creado como motor para la inversión en el proceso de regionalización del gobierno militar, el cual no ha sido modificado en la actualidad, y por último cabe mencionar que las repercusiones de la "ley indígena" son aún imprevisibles, dado que la Corporación de Desarrollo Indígena (CONADI) aún no consolida su presencia en la zona.

Esta nueva forma de concebir el poder local tiene especial repercusión en localidades como San Pedro de Atacama, en donde por primera vez en su historia (septiembre de 1992), se constituye el Consejo Municipal democráticamente elegido. Pensamos que si bien éste no es un cambio radical en cuanto al rol aculturador que le ha cabido a la presencia del Estado en la región, sí pueden ser las bases de interesantes cambios hacia la autogestión del desarrollo. Probablemente, este tipo de autogestión no tiene toda la envergadura deseable, pero es una experiencia nueva para comunidades como San Pedro de Atacama. No es posible pretender dar la última palabra sobre el futuro de los atacameños, se están sucediendo una serie de cambios tanto aculturadores como de reafirmación étnica, en donde el resultado final no es posible aventurarlo, por lo demás no será la primera vez que la realidad supere a la teoría.

\section{REFERENCIAS CITADAS}

ARANDA, X., 1964. San Pedro de Atacama. Elementos diagnósticos para un plan de desarrollo local. Informaciones Geográficas, número único, pp. 19-61.

CAJIAS, F., 1975. La Provincia de Atacama (1825-1842). Instituto Boliviano de Cultura, La Paz.

ENCINA, F., 1962. Historia de Chile. Editora Zig-Zag, Santiago.

GONZALEZ, S., C. MALDONADO y S. MCGEE DEUTSCH, 1993. Ligas patrióticas. Revista de Investigaciones Científicas y Tecnológicas 2: 26-35.

HEISE, J., 1979. 150 años de evolución institucional. Editorial Andrés Bello, Santiago.

LOBOS, J. L., 1953. La agricultura en San Pedro de Atacama. Ministerio de Agricultura, Antofagasta.

MORANDE, P., 1984. Cultura y modernización en América Latina. Pontificia Universidad Católica de Chile, Santiago.

MURRA, J., 1976. Los límites y las limitaciones del archipiélago vertical en los Andes. El Homenaje al
Dr. Gustavo Le Paige s. j., pp. 141-146. Universidad del Norte, Antofagasta.

NUÑEZ, L., 1992. Cultura y conflicto en los oasis de San Pedro de Atacama. Editorial Universitaria, Santiago.

NUÑEZ, L. y T. DILLEHAY, 1979. Movilidad giratoria. Armonía social y desarrollo en los Andes: Patrones de tráfico e interacción económica (ensayo). Universidad del Norte, Antofagasta.

POLANYI, K., 1992 [1957]. La gran transformación. Fondo de Cultura Económica, México D. F.

RIVERA, F., 1992Ms. Symbolic-administrative variables in the process of aculturising in San Pedro de Atacama.

1993Ms. La marginalidad como proceso dual en San Pedro de Atacama. Informe DGICT, Universidad Católica del Norte, Antofagasta.

TALLER DE ESTUDIOS ANDINOS, 1993Ms. Informe de avance. Proyecto DURR ORSTOM, Universidad Católica del Norte, Antofagasta. 